Utah State University

DigitalCommons@USU

Space Dynamics Lab Publications

Space Dynamics Lab

$1-1-2006$

\title{
SOFIE Instrument Ground Calibration
}

Scott Hansen

Chad Fish

Devin Romrell

Larry Gordley

Mark Hervig

Follow this and additional works at: https://digitalcommons.usu.edu/sdl_pubs

\section{Recommended Citation}

Hansen, Scott; Fish, Chad; Romrell, Devin; Gordley, Larry; and Hervig, Mark, "SOFIE Instrument Ground Calibration" (2006). Space Dynamics Lab Publications. Paper 56.

https://digitalcommons.usu.edu/sdl_pubs/56

This Article is brought to you for free and open access by the Space Dynamics Lab at DigitalCommons@USU. It has been accepted for inclusion in Space Dynamics Lab Publications by an authorized administrator of DigitalCommons@USU. For more information, please contact digitalcommons@usu.edu.

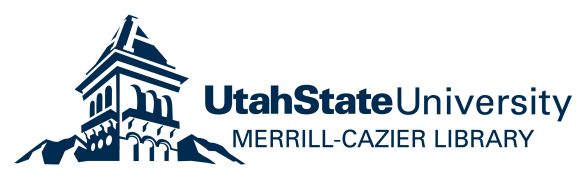




\author{
SOFIE Instrument Ground Calibration \\ Scott Hansen ${ }^{1}$, Chad Fish ${ }^{1}$, Devin Romrell ${ }^{1}$, Larry Gordley ${ }^{2}$, Mark Hervig ${ }^{3}$ \\ ${ }^{1}$ Space Dynamics Laboratory/Utah State University \\ 1695 North Research Park Way, North Logan, UT 84341 \\ ${ }^{2}$ GATS, Inc. \\ 11864 Canon Blvd., Newport News, VA 23606 \\ ${ }^{3}$ GATS, Inc. \\ P.O. Box 449, Driggs, ID 83422
}

\begin{abstract}
Space Dynamics Laboratory (SDL), in partnership with GATS, Inc., designed and built an instrument to conduct the Solar Occultation for Ice Experiment (SOFIE). SOFIE is the primary infrared sensor in the NASA Aeronomy of Ice in the Mesosphere (AIM) instrument suite. AIM's mission is to study polar mesospheric clouds (PMCs). SOFIE will make measurements in 16 separate spectral bands, arranged in eight pairs between 0.29 and $5.3 \mu \mathrm{m}$. Each band pair will provide differential absorption limb-path transmission profiles for an atmospheric component of interest, by observing the sun through the limb of the atmosphere during solar occultation as AIM orbits Earth. A pointing mirror and imaging sun sensor coaligned with the detectors are used to track the sun during occultation events and maintain stable alignment of the sun on the detectors.

Ground calibration experiments were performed to measure SOFIE end-to-end relative spectral response, nonlinearity, and spatial characteristics. SDL's multifunction infrared calibrator \#1 (MIC1) was used to present sources to the instrument for calibration. Relative spectral response (RSR) measurements were performed using a step-scan Fourier transform spectrometer (FTS). Out-of-band RSR was measured to approximately $0.01 \%$ of in-band peak response using the cascaded filter Fourier transform spectrometer (CFFTS) method. Linearity calibration was performed using a calcium fluoride attenuator in combination with a 3000K blackbody. Spatial characterization was accomplished using a point source and the MIC1 pointing mirror. SOFIE sun sensor tracking algorithms were verified using a heliostat and relay mirrors to observe the sun from the ground. These techniques are described in detail, and resulting SOFIE performance parameters are presented.
\end{abstract}

Keywords: SOFIE, calibration, solar, infrared

\title{
1. INTRODUCTION
}

SOFIE (Solar Occultation for Ice Experiment) is the primary infrared sensor in the AIM suite of instruments. The SOFIE instrument design is based on the highly successful Upper Atmosphere Research Satellite (UARS) Halogen Occultation Experiment (HALOE) instrument. SOFIE will perform satellite solar occultation measurements to obtain limb-path broadband transmission profiles, which will be used to determine profiles of temperature/pressure, mixing ratio profiles of five gaseous species $(\mathrm{O} 3, \mathrm{H} 2 \mathrm{O}, \mathrm{CO} 2, \mathrm{CH} 4$, and $\mathrm{NO}$ ), and polar mesospheric cloud (PMC) particle extinction.

The instrument will use the differential absorption radiometry approach, with eight channel pairs covering wavelengths ( $\lambda$ ) from 0.29 to $5.32 \mu \mathrm{m}$. In this technique, specific gases are targeted by measuring solar intensity in two wavelength regions, one where the gas is strongly absorbing and an adjacent region where the gas is weakly absorbing. Measuring the difference between the strong and weak band signals has numerous advantages, including the reduction of undesired instrumental effects, and the reduction of atmospheric interference. Six SOFIE channels are designed to measure gaseous signals, and two are dedicated to particle measurements. Measurements in two $\mathrm{CO}_{2}$ bands will be used to simultaneously retrieve temperature and $\mathrm{CO}_{2}$ mixing ratio. In addition to the main science channels, SOFIE includes an imaging sun sensor and steering mirror assembly (SMA) for pointing control.

Infrared Spaceborne Remote Sensing XIV, edited by Marija Strojnik, Proc. of SPIE

Vol. 6297, 62970J, (2006) · 0277-786X/06/\$15 · doi: 10.1117/12.681164 


\section{SOFIE CALIBRATION APPROACH}

The goal of IR instrument calibration is to independently characterize each calibration parameter. However, during actual measurements, it may not be possible to totally separate the measurement domain from other effects. These effects must be identified and separately characterized for successful calibration. Complete characterization includes an estimate of the uncertainty associated with each parameter.

A necessary step in the calibration process is to identify those parameters that completely characterize the sensor. These equations and associated parameters can be conveniently grouped into two categories: calibration equation parameters and radiometric model parameters. The calibration equation contains parameters that are needed to relate sensor output to measured flux in engineering units such as watts $/ \mathrm{cm}^{2} \cdot \mathrm{sr}$. The measured flux is related to the true scene flux using calibration parameters from the radiometric model. The radiometric model contains those calibration parameters that are not part of the calibration equation but that are needed to completely characterize the sensor. Together, the calibration equation and radiometric model parameters describe the responsivity of the sensor, including spatial, spectral, and temporal response characteristics.

\subsection{Calibration Equation}

The SOFIE instrument operates by processing the signal from each band in a differential absorption pair to yield a direct signal from each band, and a difference signal for the pair. These signals are converted to digital outputs proportional to volts for further processing. The direct signal output from a given detector was used for most ground calibration measurements. For a given detector, the calibration equation for the direct signal output is given by

$$
N_{d}=1\left(£_{A D C}\left(G_{d}\left(r_{d}\right)\right)\right)
$$

where the parameters are as identified in Table 1.

Table 1. Direct Response Calibration Equation Parameters

\begin{tabular}{|l|c|}
\hline \multicolumn{1}{|c|}{ Parameter } & Symbol \\
\hline Digitized detector response [counts] & $N_{d}$ \\
\hline Linearity correction function & 1 \\
\hline ADC coefficient [counts per volt] & $£_{A D C}$ \\
\hline Electronics gain [unitless] & $G_{d}$ \\
\hline Detector response [volts] & $r_{d}$ \\
\hline Detector index - parameter is unique to each detector & $d$ \\
\hline
\end{tabular}

The calibration equation for the difference signal from a differential absorption detector pair is given by

$$
N_{\text {diff }}=£_{A D C} G_{\text {diff }}\left(G_{w}\left(r_{w}\right)-G_{s}\left(r_{s}\right)\right)
$$

where the parameters are identified in Table 2.

Table 2. Differential Response Calibration Equation Parameters

\begin{tabular}{|l|c|}
\hline \multicolumn{1}{|c|}{ Parameter } & Symbol \\
\hline Digitized differential response [counts] & $N_{\text {diff }}$ \\
\hline ADC coefficient [counts per volt] & $£_{A D C}$ \\
\hline Differential gain [unitless] & $G_{\text {diff }}$ \\
\hline Weakly absorbing channel adjustable gain [unitless] & $G_{w}$ \\
\hline Weakly absorbing preamplified response [volts] & $r_{w}$ \\
\hline
\end{tabular}




\begin{tabular}{|l|c|}
\hline \multicolumn{1}{|c|}{ Parameter } & Symbol \\
\hline Strongly absorbing channel adjustable gain [unitless] & $G_{s}$ \\
\hline Strongly absorbing preamplified response [volts] & $r_{c}$ \\
\hline
\end{tabular}

The differential measurement technique employed for SOFIE, and illustrated by Equation (2), reduces the effects of noise and atmospheric interference in the measurement. This approach also simplifies calibration by eliminating the need for absolute radiometric characterization.

The difference signal described by Equation (2) is produced in the instrument itself, eliminating the possibility of difference signal linearity correction, and as such no linearity correction function is shown in the equation. Analysis of the system performance, including expected non-linearity remaining in the direct signal outputs, predicts acceptable difference signal performance. Difference signal analysis using linearity corrected data may be performed in data processing following data collection, using the corrected data described in Equation (1).

\subsection{Radiometric Model}

The SOFIE radiometric model characterizes the spectral, spatial, and temporal responsivity domains of the sensor. The spectral domain will be characterized by the in-band and out-of-band relative spectral response. The spatial domain will be characterized by the detector field of view and detector co-alignment. The temporal domain will be characterized by the sensor response stability and repeatability. The calibration parameters included in the radiometric model are listed in Table 3.

Table 3. Radiometer Radiometric Model Calibration Parameters

\begin{tabular}{|l|c|}
\hline \multicolumn{1}{|c|}{ Parameter } & Symbol \\
\hline Relative spectral responsivity & $R S R\left(\lambda_{d}\right)$ \\
\hline Effective field of view & $\Omega e f f_{d}$ \\
\hline Detector coalignment & $\Delta \theta_{d}$ \\
\hline Illuminated short-term repeatability (noise) & $\sigma_{s t}$ \\
\hline Illuminated short-term stability (drift) & $\sigma_{m t}$ \\
\hline
\end{tabular}

\section{SOFIE CALIBRATION EQUIPMENT}

Measuring the parameters of the SOFIE calibration equation and radiometric model required multiple source configurations. The SOFIE instrument was placed in a vacuum chamber with temperature controlled surfaces to provide thermal control and simulate the space environment, and multiple source configurations were interfaced to the vacuum chamber through a calcium fluoride window.

\subsection{Calibration Chamber}

A cutaway drawing of the SOFIE calibration chamber is shown in Figure 1. Temperature controlled shrouds used to maintain and stabilize SOFIE operating temperature during calibration are shown. The calcium fluoride window through which various sources were introduced to the SOFIE instrument is visible, and SOFIE instrument and the electronics box location are also illustrated. SOFIE operating temperature conditions used during calibration are called out in Table 4, with corresponding data collection procedures at each temperature. 


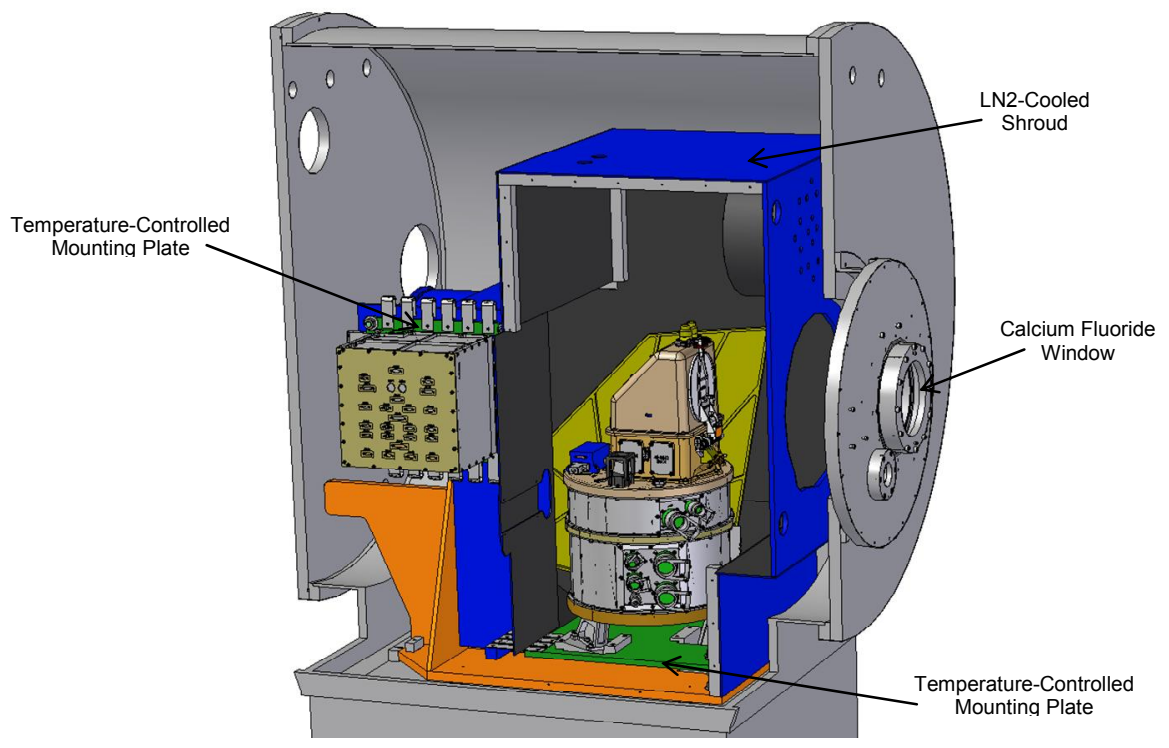

Figure 1. SOFIE Calibration Thermal Environment

Table 4. SOFIE Calibration Operating Temperatures

\begin{tabular}{|c|c|c|c|}
\hline $\begin{array}{c}\text { Operating Temperature } \\
\text { Config. }\end{array}$ & $\begin{array}{c}\text { Optics / Filters / } \\
\text { Detectors Temperature }\end{array}$ & $\begin{array}{c}\text { Electronics } \\
\text { Temperature }\end{array}$ & Data Collection Procedures \\
\hline Cold & $-35 \mathrm{C}$ & $0 \mathrm{C}$ & RSR, FOV \\
\hline Nominal & $-20 \mathrm{C}$ & $+15 \mathrm{C}$ & $\begin{array}{c}\text { RSR, Linearity, FOV, Temporal } \\
\text { Response, Stability \& Noise }\end{array}$ \\
\hline Warm & $+5 \mathrm{C}$ & $+40 \mathrm{C}$ & RSR, FOV \\
\hline
\end{tabular}

\subsection{Multifunction Calibrator}

For all spectral response testing, and for most radiometric, spatial and temporal domain testing, the SOFIE instrument observed sources through a multifunction infrared calibrator (MIC1). This calibrator provides a 100-inch-long focal length collimator with interchangeable apertures. A flat pointing mirror provides beam steering capability over 10 degrees in two axes. External sources are focused into the collimator to generate the output beam. Sources used with the MIC1 collimator include a high temperature blackbody and Fourier Transform Spectrometer (FTS). Collimator apertures used during SOFIE calibration are listed in Table 5, with associated data collection procedures.

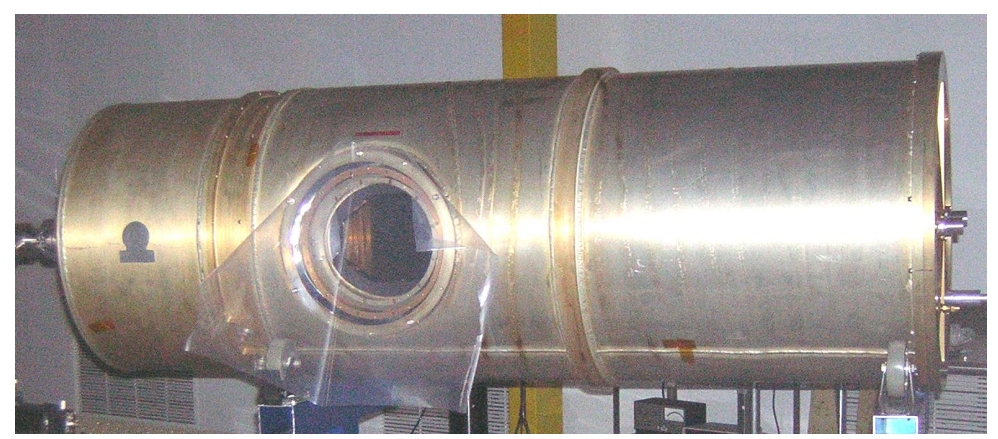

Figure 2. Multifunction Infrared Calibrator \#1 
Table 5. MIC1 Collimator Apertures

\begin{tabular}{|c|c|c|c|}
\hline Position & Diameter & Divergence & Data Collection Procedures \\
\hline 5 & $0.0224 \mathrm{in.}$ & $0.224 \mathrm{mrad}(0.77 \mathrm{arcmin})$ & On-Axis FOV \\
\hline 7 & $0.0447 \mathrm{in.}$ & $0.447 \mathrm{mrad}(1.54 \mathrm{arcmin})$ & Off-Axis FOV \\
\hline 13 & Open & Open & $\begin{array}{c}\text { RSR, Linearity, Temporal } \\
\text { Response, Stability \& Noise }\end{array}$ \\
\hline 14 & Rectangle & $\begin{array}{c}0.265 \mathrm{in.} \mathrm{X} 0.175 \mathrm{in} . \\
(9.11 \mathrm{amin} \mathrm{X} 6.02 \mathrm{amin})\end{array}$ & Knife Edge \\
\hline
\end{tabular}

\subsection{Solar Emulator Blackbody}

For radiometric, spatial and temporal domain test during SOFIE calibration, a high temperature blackbody was placed directly at the input to MIC1. The MIC1 steering mirror provided movement of the source throughout the SOFIE field of view. The solar emulator blackbody (SEBB) provided temperatures up to $3000 \mathrm{~K}$. An Argon purge is required to avoid damage to the blackbody cavity at these temperatures. A photograph of the solar simulator blackbody is shown in Figure 3.

\subsection{Fourier Transform Spectrometer}

A Fourier Transform Spectrometer (FTS) was used with MIC1 to provide a source for SOFIE spectral calibration. A photograph of this instrument is shown in Figure 4. The FTS was placed at the $\mathrm{MIC1}$ input, and a $\mathrm{CaF}_{2}$ lens was used to focus the FTS output onto the MIC1 aperture.

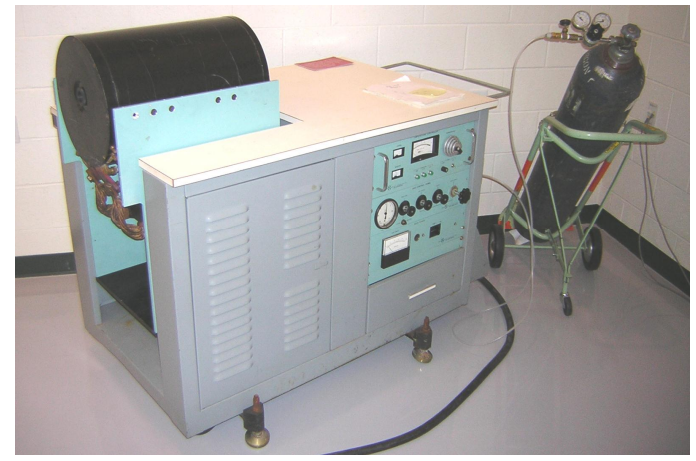

Figure 3. Solar Emulator Blackbody

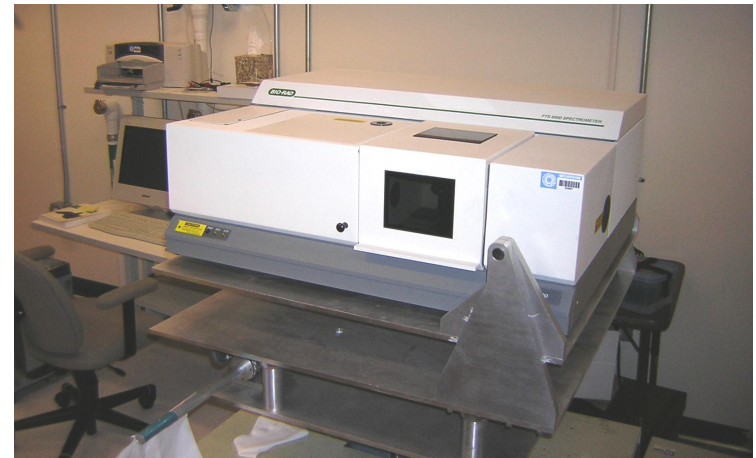

Figure 4. Fourier Transform Spectrometer

The MIC1 spectral calibration configuration was characterized separately from SOFIE calibration to determine the relative spectral content of the MIC1 output. This measurement is based on spectral characterization of large-area spectral reference detectors and forms the basis for SOFIE relative spectral response calibration. A painted lithium tantalite pyroelectric detector was used for IR wavelengths, and a silicon photodiode for visible and UV measurements.

\subsection{Heliostat}

Direct observations of solar flux were conducted during SOFIE calibration. A telescope tracking mount was used to maintain sun alignment, using software written by SDL to control the tracking stage. A 12" diameter commercial grade front surface mirror was placed on the mount, and a second mirror relayed the reflection from the first mirror into the SOFIE test chamber. A photograph of the heliostat system in operation during SOFIE calibration is shown in Figure 5. 


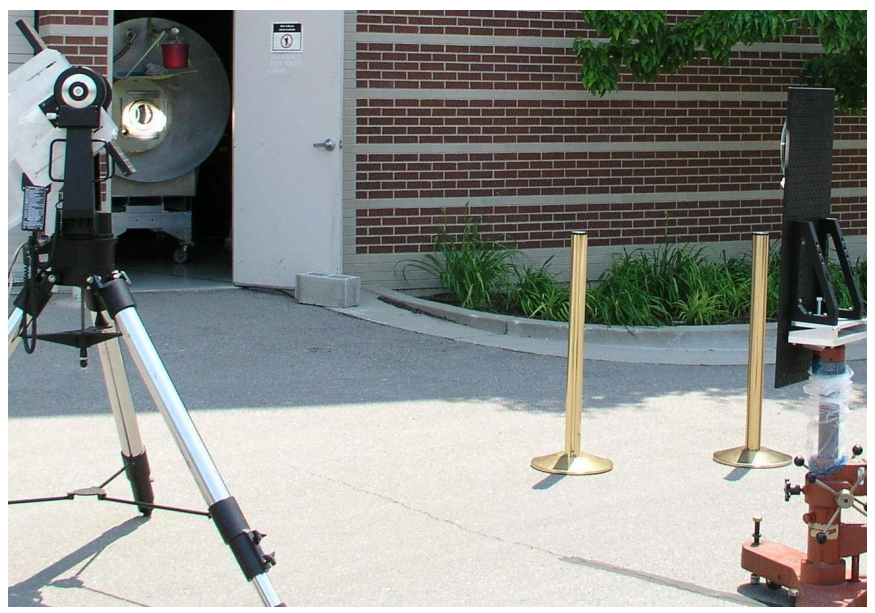

Figure 5. SOFIE Calibration Heliostat System

\section{CALIBRATION DATA ANALYSIS AND RESULTS}

Calibration experiments were conducted to provide data needed for calculation of the parameters included in the calibration equation and radiometric model. These tests were performed at the temperature conditions indicated in Table 4 to cover the expected on-orbit operational envelope.

\subsection{Relative Spectral Response}

SOFIE RSR measurements were made using the FTS shown in Figure 4. The FTS was placed on an adjustable mechanical table at the entrance port of the MIC1 collimator. The FTS provided an interference-modulated source at the MIC1 output that was sampled by the SOFIE sensor to generate interferograms from which spectral information was derived. For out-of-band RSR measurements, additional bandpass filters were used to eliminate in-band flux and characterize different out-of-band spectral regions [i]. For wavelengths less than $0.63 \mu$ m, out-of-band measurements were limited by low FTS signal, therefore out-of-band data in these regions was based on filter vendor component measurements.

The calculations required to derive RSR spectra from measured data are described by

$$
R S R_{X B}(\bar{v})=\frac{S_{R a w X B}(\bar{v})}{S(\bar{v}) \tau_{B F}(\bar{v})}\left(\frac{S T_{S R D}(\bar{v})}{S T_{I C}(\bar{v})}\right)\left(\frac{1}{K_{\text {Norm }}}\right)
$$

where

$$
\begin{array}{lll}
\operatorname{RSR}_{X B}(\bar{v}) & = & \text { measured out-of-band RSR spectrum } \\
S_{\text {RawXB }}(\bar{v}) & = & \text { out-of-band raw response spectrum } \\
S(\bar{v}) & = & \text { relative spectral intensity of exit beam (measured previously) } \\
\tau_{B F}(\bar{v}) & = & \text { blocking filter transmittance (=1 for in-band measurement) } \\
S T_{S R D}(\bar{v}) & = & \text { benchmark spectrum during reference detector measurement } \\
S T_{I C}(\bar{v}) & = & \text { benchmark spectrum during instrument calibration } \\
K_{\text {Norm }} & = & \text { in-band RSR peak normalization factor } \\
\bar{v} & = & \text { wavenumber }\left(\mathrm{cm}^{-1}\right) \text { or wavelength. }
\end{array}
$$


In-band RSR measurements were made for each individual spectral band at cold, nominal, and warm science operating temperature cases. Out-of-band RSR data were collected at nominal operating temperature only. Composite RSR plots were generated by combining in-band RSR data with selected regions of out-of-band data. Sample in-band and out-ofband RSR spectra are shown for band 8 in Figure 6 and Figure 7.

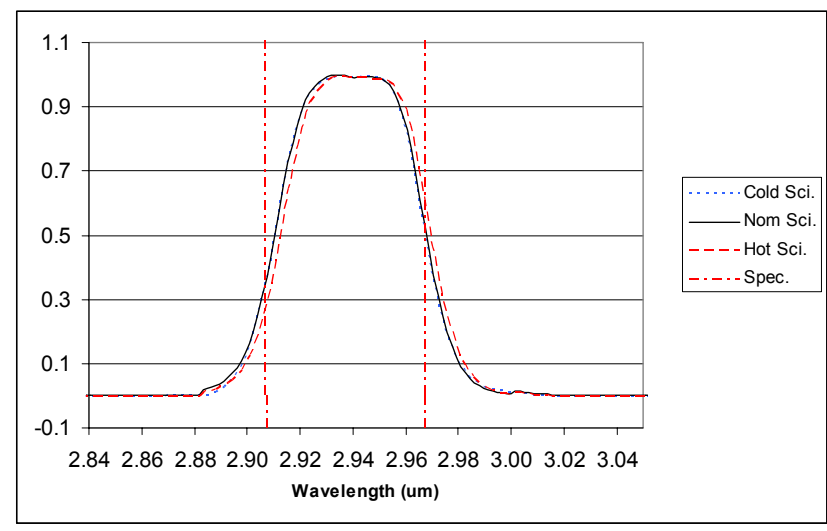

Figure 6. Band 8 RSR (In-Band)

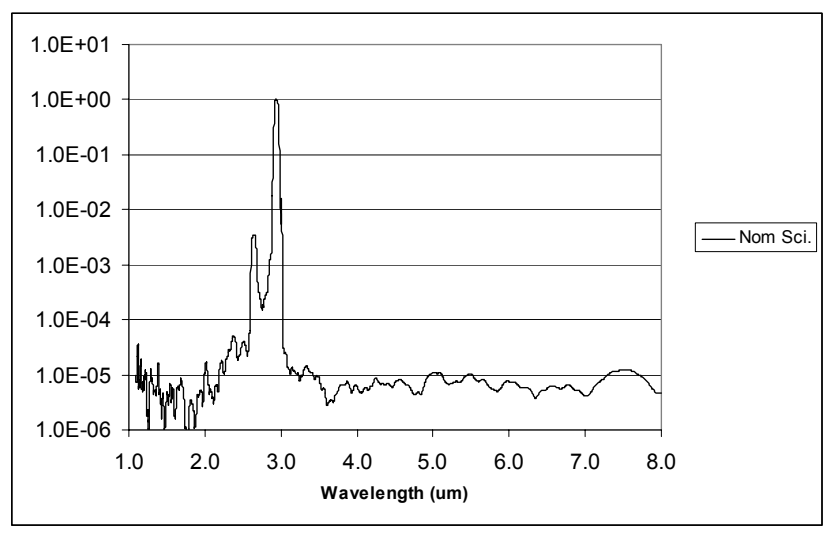

Figure 7. Band 8 RSR (Out-Of-Band)

Spectra for other SOFIE bands show similar results. Measured band limits derived from RSR calibration for all SOFIE bands are tabulated in Table 6. The product of solar flux and SOFIE RSR was integrated over the range shown in the out-of-band RSR plots, to calculate out-of-band response as a fraction of in-band response. These results are shown in Table 7.

Table 6. SOFIE Band Limits

\begin{tabular}{|c|c|c|c|c|c|}
\hline \multirow[b]{2}{*}{ Band } & \multirow{2}{*}{$\begin{array}{c}\text { Specification } \\
\text { Cuton - Cutoff } \\
(\mu \mathrm{m})\end{array}$} & \multirow{2}{*}{$\begin{array}{l}\text { Cold Science } \\
\text { Cuton-Cutoff } \\
(\mu \mathrm{m})\end{array}$} & \multicolumn{2}{|c|}{ Nominal Science } & \multirow{2}{*}{$\begin{array}{c}\text { Warm Science } \\
\begin{array}{c}\text { Cuton-Cutoff } \\
(\mu \mathrm{m})\end{array}\end{array}$} \\
\hline & & & $\begin{array}{c}\text { Cuton-Cutoff } \\
(\mu \mathrm{m})\end{array}$ & $\begin{array}{l}\text { Cuton-Cutoff } \\
\Delta \text { from spec. } \\
\quad(\mu \mathrm{m})\end{array}$ & \\
\hline 1 & $0.2857-0.2941$ & $0.2857-0.2973$ & $0.2859-0.2972$ & $0.0002-0.0031$ & $0.2862-0.2974$ \\
\hline 2 & $0.3226-0.3333$ & $0.3227-0.3374$ & $0.3227-0.3375$ & $0.0001-0.0042$ & $0.3227-0.3374$ \\
\hline 3 & $0.8475-0.8772$ & $0.8506-0.8831$ & $0.8506-0.8831$ & $0.0031-0.0059$ & $0.8510-0.8833$ \\
\hline 4 & $1.0101-1.0526$ & $1.015-1.060$ & $1.015-1.059$ & $0.0051-0.0068$ & $1.015-1.060$ \\
\hline 5 & $2.427-2.475$ & $2.436-2.488$ & $2.436-2.488$ & $0.0087-0.0127$ & $2.437-2.489$ \\
\hline 6 & $2.577-2.632$ & $2.592-2.643$ & $2.592-2.643$ & $0.0153-0.0115$ & $2.593-2.645$ \\
\hline 7 & $2.740-2.794$ & $2.757-2.813$ & $2.758-2.813$ & $0.0178-0.0190$ & $2.760-2.815$ \\
\hline 8 & $2.907-2.967$ & $2.910-2.968$ & $2.910-2.968$ & $0.0034-0.0009$ & $2.912-2.970$ \\
\hline 9 & $3.030-3.091$ & $3.034-3.093$ & $3.035-3.093$ & $0.0046-0.0025$ & $3.037-3.095$ \\
\hline 10 & $3.160-3.226$ & $3.152-3.219$ & $3.152-3.219$ & $-0.0076--0.0066$ & $3.154-3.221$ \\
\hline 11 & $3.333-3.401$ & $3.344-3.421$ & $3.345-3.422$ & $0.0121-0.0212$ & $3.350-3.427$ \\
\hline 12 & $3.472-3.546$ & $3.444-3.513$ & $3.445-3.514$ & $-0.0272--0.0322$ & $3.450-3.518$ \\
\hline 13 & $4.255-4.444$ & $4.219-4.427$ & $4.220-4.428$ & $-0.0352--0.0163$ & $4.226-4.432$ \\
\hline 14 & $4.630-4.740$ & $4.577-4.709$ & $4.581-4.712$ & $-0.0491--0.0280$ & $4.595-4.724$ \\
\hline 15 & $4.951-5.051$ & $4.957-5.051$ & $4.959-5.053$ & $0.0080-0.0016$ & $4.968-5.060$ \\
\hline 16 & $5.263-5.376$ & $5.232-5.394$ & $5.236-5.396$ & $-0.0275-0.0200$ & $5.250-5.410$ \\
\hline
\end{tabular}

Table 7. SOFIE Out-of-Band Response

\begin{tabular}{|c|c|}
\hline Band & Out-of-Band Response (\%) \\
\hline 1 & 2.6 \\
\hline 2 & 0.03 \\
\hline 3 & 2.1 \\
\hline 4 & 1.6 \\
\hline 5 & 1.0 \\
\hline
\end{tabular}




\begin{tabular}{|c|c|}
\hline Band & Out-of-Band Response (\%) \\
\hline 6 & 1.1 \\
\hline 7 & 0.5 \\
\hline 8 & 1.0 \\
\hline 9 & 0.3 \\
\hline 10 & 0.3 \\
\hline 11 & 0.6 \\
\hline 12 & 0.7 \\
\hline 13 & 0.1 \\
\hline 14 & 0.4 \\
\hline 15 & 1.1 \\
\hline 16 & 0.5 \\
\hline
\end{tabular}

\subsection{Linearity Correction}

Initial calibration of the SOFIE instrument revealed unacceptable nonlinearity in bands $5-16$. This behavior was traced to nonlinear behavior in $\mathrm{HgCdTe}$ detectors when the irradiance (flux per area) on the detectors exceeds a certain level [ii]. Changes to the instrument design were introduced to reduce the non-linearity to acceptable levels and to provide a means for expanded characterization of the remaining non-linearity. These changes involved reducing the irradiance on detectors $5-16$ by adjusting the detector position so that the detectors are overfilled rather than underfilled, and adding a 33\% transmissive neutral-density (ND) filter in the optical path to further reduce flux on the detectors. The ND filter provided the additional advantage that by testing before installation of the ND filter, measurements could be made at higher levels in the dynamic range.

SOFIE response linearity was calibrated by stimulating the instrument over as wide a dynamic range as possible while chopping a $\mathrm{CaF}_{2}$ window through the incoming beam. This small attenuator method allows derivation of a linearity correction function by analysis of the change in measured window transmittance as a function of instrument response. The SEBB source (see Figure 3) used for these tests achieved an effective emitting temperature of $\sim 3000 \mathrm{~K}$, which equates to roughly $33 \%$ of the exoatmospheric solar radiance expected on orbit. Stimulating SOFIE with the SEBB with the flight ND filter removed thus achieved maximum radiance levels near those expected with the ND filter installed.

A sample small attenuator calibration time series is shown in Figure 8. A plot of measured window transmission versus response is shown for band 8 in Figure 9. These data were fit with a line of the form

$$
\tau_{W M}=C_{1}+C_{2} N_{m}
$$

where

$$
\begin{array}{lll}
\tau_{W M} & = & \text { measured small attenuator transmittance } \\
C_{1} & = & \text { constant (=absolute window transmittance) } \\
C_{2} & = & \text { constant (=transmittance change versus response) } \\
N_{m} & = & \text { measured sensor response. }
\end{array}
$$

For system nonlinearity modeled as the product of ideal (linear) system response and a non-linearity function as shown here,

$$
N_{M}=N_{L} F_{N L}\left(N_{M}\right)
$$

where

$\begin{array}{lll}N_{M} & = & \text { measured sensor response } \\ N_{L} & = & \text { ideal (linear) response } \\ F_{N L}\left(N_{M}\right) & = & \text { non-linearity function, }\end{array}$

it can be shown that 


$$
F_{N L}\left(N_{M}\right)=1-C_{N L} N_{M}
$$

where

$$
C_{N L}=\frac{C_{2}}{1-C_{1}}
$$

Non-linearity calibration results derived using this method for bands 5-16 are summarized in Table 8. Uncertainty for all bands is determined by analysis of curve fit residuals using data similar to that shown in Figure 9.

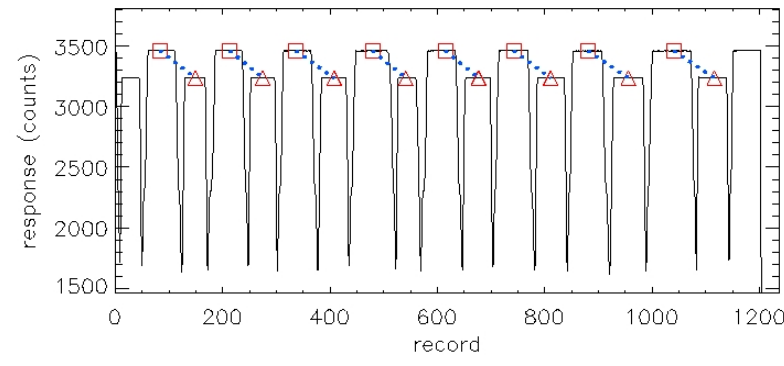

Figure 8. Small Attenuator Time Series

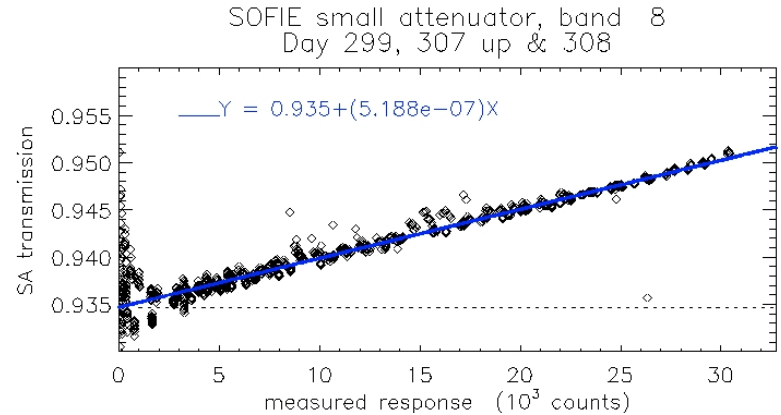

Figure 9. Small Attenuator Transmittance

\begin{tabular}{|c|c|c|c|c|c|}
\hline Channel & $\begin{array}{c}\text { Band / } \\
\text { Target* }\end{array}$ & $\begin{array}{c}\text { Center } \lambda \\
(\mu \mathrm{m})\end{array}$ & Detector & $C_{N L}($ counts- 1$)$ & $\begin{array}{l}\text { Nonlinearity }(\%) \text { at } 2^{15} \\
\text { counts / uncertainty }(\%)\end{array}$ \\
\hline \multirow{2}{*}{1} & $1 / \mathrm{O}_{3} \mathrm{~s}$ & 0.290 & \multirow{2}{*}{$\mathrm{SiC}, \mathrm{PV}$} & 0 & 0 \\
\hline & $2 / \mathrm{O}_{3} \mathrm{w}$ & 0.328 & & 0 & 0 \\
\hline \multirow{2}{*}{2} & $3 / \mathrm{PMC} \mathrm{s}$ & 0.862 & \multirow{2}{*}{$\mathrm{Ge}, \mathrm{PV}$} & 0 & 0 \\
\hline & 4 / PMC w & 1.03 & & 0 & 0 \\
\hline \multirow{2}{*}{3} & $5 / \mathrm{H}_{2} \mathrm{O} w$ & 2.45 & \multirow{2}{*}{$\mathrm{HgCdTe}, \mathrm{PC}$} & $1.68 \times 10-6$ & $5.5 / 0.3$ \\
\hline & $6 / \mathrm{H}_{2} \mathrm{O} \mathrm{s}$ & 2.60 & & $1.46 \times 10-6$ & $4.8 / 0.3$ \\
\hline \multirow{2}{*}{4} & $7 / \mathrm{CO}_{2} \mathrm{~s}$ & 2.77 & \multirow{2}{*}{$\mathrm{HgCdTe}, \mathrm{PC}$} & $8.91 \times 10-6$ & $29.2 / 0.2$ \\
\hline & $8 / \mathrm{CO}_{2} \mathrm{w}$ & 2.94 & & $7.94 \times 10-6$ & 26.00 .2 \\
\hline \multirow{2}{*}{5} & 9/PMC s & 3.06 & \multirow{2}{*}{$\mathrm{HgCdTe}, \mathrm{PC}$} & $6.63 \times 10-7$ & $2.2 / 0.2$ \\
\hline & $10 / \mathrm{PMC} \mathrm{w}$ & 3.19 & & $1.47 \times 10-6$ & $4.8 / 0.2$ \\
\hline \multirow{2}{*}{6} & $11 / \mathrm{CH}_{4} \mathrm{~s}$ & 3.37 & \multirow{2}{*}{$\mathrm{HgCdTe}, \mathrm{PC}$} & $1.46 \times 10-6$ & $4.8 / 0.2$ \\
\hline & $12 / \mathrm{CH}_{4} \mathrm{~W}$ & 3.51 & & $2.23 \times 10-6$ & $7.3 / 0.2$ \\
\hline \multirow{2}{*}{7} & $13 / \mathrm{CO}_{2} \mathrm{~s}$ & 4.25 & \multirow{2}{*}{$\mathrm{HgCdTe}, \mathrm{PC}$} & $4.83 \times 10-6$ & $15.8 / 0.7$ \\
\hline & $14 / \mathrm{CO}_{2} \mathrm{~W}$ & 4.63 & & $3.20 \times 10-6$ & $10.5 / 0.9$ \\
\hline \multirow{2}{*}{8} & $15 / \mathrm{NO} w$ & 4.98 & \multirow{2}{*}{$\mathrm{HgCdTe}, \mathrm{PC}$} & $1.75 \times 10-6$ & $5.7 / 0.2$ \\
\hline & $16 / \mathrm{NO} s$ & 5.32 & & $2.26 \times 10-6$ & $7.4 / 0.3$ \\
\hline
\end{tabular}

Table 8. SOFIE Nonlinearity Correction Constants

\subsection{Field-of-View}

SOFIE field-of-view (FOV) characterization measurements were made using a combination of methods. For the IR channels (bands 3 to 16), the MIC1 collimator was used with the SEBB source to steer a point source (0.022-inch aperture) in a grid pattern over the SOFIE FOV (1.8 x 6.0 arcmin nominal), while for bands 1 and 2, a UV Xenon arc lamp was used to scan a knife-edge across the SOFIE aperture. FOV full-width at half-maximum (FWHM) and FOV 
mismatches for all SOFIE bands are summarized in Table 9. The uncertainty shown for bands 3 to 16 is the standard deviation of measurements at each of the operating temperatures shown in Table 4. Multiple knife-edge FOV measurements for bands 1 and 2 were not possible, therefore an uncertainty analysis for these bands was made based on a comparison of point source and knife-edge FOV measurements using data for bands 3 and 4.

Table 9. SOFIE Field-Of-View

\begin{tabular}{|c|c|c|c|c|c|}
\hline \multirow[b]{2}{*}{ Chan. } & \multirow{2}{*}{$\begin{array}{l}\text { Band / } \\
\text { Target }\end{array}$} & \multicolumn{2}{|c|}{ Elevation FWHM } & \multicolumn{2}{|c|}{ Elevation Mismatch } \\
\hline & & $\begin{array}{l}\text { Mean FWHM } \\
\text { (arcmin) }\end{array}$ & $\begin{array}{l}\text { Uncertainty } \\
\text { (arcmin) }\end{array}$ & $\begin{array}{l}\text { Mean Centroid } \\
\text { Offset (arcmin) }\end{array}$ & $\begin{array}{l}\text { Uncertainty } \\
\text { (arcmin) }\end{array}$ \\
\hline \multirow{2}{*}{1} & $1 / \mathrm{O}_{3} \mathrm{~s}$ & 1.43 & 0.15 & 0.04 & 0.01 \\
\hline & $2 / \mathrm{O}_{3} \mathrm{~W}$ & 1.64 & 0.15 & 0.02 & 0.01 \\
\hline \multirow{2}{*}{2} & $3 / \mathrm{PMC}$ & 1.83 & 0.09 & $\mathrm{~N} / \mathrm{A}$ & N/A \\
\hline & 4 / PMC & 1.82 & 0.09 & 0.00 & 0.01 \\
\hline \multirow{2}{*}{3} & $5 / \mathrm{H}_{2} \mathrm{O}$ w & 1.91 & 0.06 & -0.01 & 0.03 \\
\hline & $6 / \mathrm{H}_{2} \mathrm{O} \mathrm{s}$ & 1.98 & 0.07 & -0.05 & 0.01 \\
\hline \multirow{2}{*}{4} & $7 / \mathrm{CO}_{2} \mathrm{~s}$ & 2.08 & 0.09 & -0.08 & 0.01 \\
\hline & $8 / \mathrm{CO}_{2} \mathrm{w}$ & 2.05 & 0.12 & -0.11 & 0.01 \\
\hline \multirow{2}{*}{5} & $9 / \mathrm{PMC}$ & 1.99 & 0.07 & -0.03 & 0.03 \\
\hline & 10 / PMC & 1.91 & 0.08 & -0.05 & 0.01 \\
\hline \multirow{2}{*}{6} & $11 / \mathrm{CH}_{4} \mathrm{~s}$ & 2.09 & 0.11 & -0.04 & 0.00 \\
\hline & $12 / \mathrm{CH}_{4} \mathrm{~W}$ & 1.90 & 0.13 & -0.05 & 0.00 \\
\hline \multirow{2}{*}{7} & $13 / \mathrm{CO}_{2} \mathrm{~s}$ & 1.96 & 0.11 & 0.04 & 0.01 \\
\hline & $14 / \mathrm{CO}_{2} \mathrm{~W}$ & 1.94 & 0.10 & 0.02 & 0.01 \\
\hline \multirow{2}{*}{8} & $15 / \mathrm{NO} \mathrm{w}$ & 1.96 & 0.10 & -0.02 & 0.01 \\
\hline & $16 / \mathrm{NO} s$ & 1.95 & 0.12 & 0.09 & 0.01 \\
\hline
\end{tabular}

\subsection{Gain Characterization}

Gain characterization measurements for bands 3 to 16 were performed by observing the SEBB source through the MIC1 collimator. A range of SEBB temperatures was chosen to provide response over as much of the measurement dynamic range as possible. System gains for bands 1 and 2 were based on solar observations using the heliostat system shown in Figure 5, combined with Beer's law analysis of atmospheric transmission. Band 1 was unable to observe the sun through the atmosphere, therefore band 1 system gain was extrapolated by analysis from band 2 measurements. Gain characterization results are summarized in Table 10. The gain error shown refers to the anticipated change in signal gain required to achieve full scale response at maximum illumination on orbit. The SOFIE instrument was designed to allow gain changes to accommodate errors on the order of those shown.

Table 10. Gain Summary

\begin{tabular}{|c|c|c|c|}
\hline Channel & Band/Target & $\begin{array}{c}\text { Gain Error (\%) } \\
\text { (cold / nom / warm) }\end{array}$ & \multirow{2}{*}{$\begin{array}{c}\Delta \text { V Gain } \\
\text { (Spec / Measured) }\end{array}$} \\
\hline \multirow{2}{*}{1} & $1 / \mathrm{O}_{3} \mathrm{~s}$ & $23-34$ & \multirow{2}{*}{$30 / 39.7$} \\
\cline { 2 - 3 } & $2 / \mathrm{O}_{3} \mathrm{w}$ & $23-34$ & \multirow{2}{*}{$300 / 303.4$} \\
\hline \multirow{2}{*}{2} & $3 / \mathrm{PMC}$ & $-6.8 /-4.3 /-3.6$ & \multirow{2}{*}{$96 / 96.6$} \\
\cline { 2 - 3 } & $4 / \mathrm{PMC}$ & $3.0 / 4.8 / 3.9$ & \multirow{2}{*}{$110 / 109.4$} \\
\hline \multirow{2}{*}{3} & $5 / \mathrm{H}_{2} \mathrm{O} \mathrm{w}$ & $1.4 / 0.0 /-7.2$ & \multirow{2}{*}{10.4} \\
\cline { 2 - 3 } & $6 / \mathrm{H}_{2} \mathrm{O} \mathrm{s}$ & $11.4 / 8.5 /-0.8$ & \\
\hline \multirow{2}{*}{4} & $7 / \mathrm{CO}_{2} \mathrm{~s}$ & $-9.7 /-10.7 /-14.5$ & \\
\cline { 2 - 4 } & $8 / \mathrm{CO}_{2} \mathrm{w}$ & $-4.8 /-5.5 /-8.8$ & \\
\hline
\end{tabular}




\begin{tabular}{|c|c|c|c|}
\hline Channel & Band/Target & $\begin{array}{c}\text { Gain Error (\%) } \\
\text { (cold / nom / warm) }\end{array}$ & \multirow{2}{*}{$\begin{array}{c}\Delta \text { V Gain } \\
\text { (Spec / Measured) }\end{array}$} \\
\hline \multirow{2}{*}{5} & $9 / \mathrm{PMC}$ & $2.6 / 0.9 /-3.1$ & \multirow{2}{*}{$120 / 120.0$} \\
\cline { 2 - 3 } & $10 / \mathrm{PMC}$ & $13.0 / 12.8 / 8.5$ & \multirow{2}{*}{$202 / 202.8$} \\
\hline \multirow{2}{*}{6} & $11 / \mathrm{CH}_{4} \mathrm{~s}$ & $8.6 / 7.7 / 3.8$ & \multirow{2}{*}{$110 / 110.3$} \\
\cline { 2 - 3 } & $12 / \mathrm{CH}_{4} \mathrm{w}$ & $-12.1 /-12.2 /-16.1$ & \multirow{2}{*}{$300 / 297.3$} \\
\hline \multirow{2}{*}{7} & $13 / \mathrm{CO}_{2} \mathrm{~s}$ & $2.1 / 1.3 /-3.1$ & \multirow{2}{*}{$20.7 / 4.9 /-6.8$} \\
\cline { 2 - 3 } & $14 / \mathrm{CO}_{2} \mathrm{w}$ & $10.0 / 6.3 /-7.6$ & \\
\hline \multirow{2}{*}{8} & $15 / \mathrm{NO} \mathrm{w}$ & $9.2 / 4.8 /-9.4$ & \\
\cline { 2 - 3 } & $16 / \mathrm{NO} \mathrm{s}$ & \multicolumn{2}{|c}{} \\
\hline
\end{tabular}

\subsection{Signal Stability Characterization}

SOFIE stability characterization measurements were performed while viewing the SEBB source through an open position in the MIC1 aperture slide. Difference signal drift for each channel is listed in Table 11 in terms of counts per minute. Difference signal drift predictions are also shown for comparison.

Table 11. Signal Stability Summary

\begin{tabular}{|c|c|c|}
\hline Chan. & Band / Target & $\begin{array}{c}\Delta V \text { Drift } \\
\text { (counts per minute) } \\
\text { Measured / predicted }\end{array}$ \\
\hline \multirow{2}{*}{1} & $1 / \mathrm{O} 3 \mathrm{~s}$ & \multirow{2}{*}{$-2.5 /-3.9$} \\
\hline & $2 / \mathrm{O} 3 \mathrm{w}$ & \\
\hline \multirow{2}{*}{2} & 3 / PMC & \multirow{2}{*}{$-1.0 /-41.6$} \\
\hline & 4 / PMC & \\
\hline \multirow{2}{*}{3} & $5 / \mathrm{H} 2 \mathrm{O} w$ & \multirow{2}{*}{$-8.1 /-5.6$} \\
\hline & $6 / \mathrm{H} 2 \mathrm{O} \mathrm{s}$ & \\
\hline \multirow{2}{*}{4} & $7 / \mathrm{CO} 2 \mathrm{~s}$ & \multirow{2}{*}{$-9.2 /-5.8$} \\
\hline & $8 / \mathrm{CO} 2 \mathrm{w}$ & \\
\hline \multirow{2}{*}{5} & $9 / \mathrm{PMC}$ & \multirow{2}{*}{$-10.5 /-16.2$} \\
\hline & $10 / \mathrm{PMC}$ & \\
\hline \multirow{2}{*}{6} & $11 / \mathrm{CH} 4 \mathrm{~s}$ & \multirow{2}{*}{$-9.2 /-36.5$} \\
\hline & $12 / \mathrm{CH} 4 \mathrm{w}$ & \\
\hline \multirow{2}{*}{7} & $13 / \mathrm{CO} 2 \mathrm{~s}$ & \multirow{2}{*}{$39.5 / 45.0$} \\
\hline & $14 / \mathrm{CO} 2 \mathrm{w}$ & \\
\hline \multirow{2}{*}{8} & 15 / NO w & \multirow{2}{*}{$18.6 / 8.3$} \\
\hline & $16 / \mathrm{NO} s$ & \\
\hline
\end{tabular}

\subsection{Background and Noise Characterization}

SOFIE background and noise measurements were acquired while viewing a closed position in the MIC1 aperture slide. Average response under these conditions is shown in Table 12, along with difference signal signal-to-noise ratio (SNR) margin, relative to requirement. Ample margin is available for most channels.

Table 12. Noise and Background Summary

\begin{tabular}{|c|c|c|c|}
\hline \multirow{2}{*}{ Channel } & Band / Target & $\begin{array}{c}\text { Background Counts } \\
\text { (Cold / Nominal / Warm) }\end{array}$ & $\begin{array}{c}\Delta \text { V SNR Margin } \\
\text { (Cold / Nominal / Warm) }\end{array}$ \\
\hline \multirow{2}{*}{1} & $1 /$ O3 s & $8.9 / 2.4 / 10.9$ & \multirow{2}{*}{$164.1 / 148.1 / 180.6$} \\
\cline { 2 - 3 } & $2 / \mathrm{O} 3 \mathrm{w}$ & $12.8 / 12.5 / 14.0$ & \multirow{2}{*}{$5.8 / 5.8 / 5.9$} \\
\hline \multirow{2}{*}{2} & $3 / \mathrm{PMC}$ & $16.0 / 16.0 / 17.2$ & \\
\cline { 2 - 3 } & $4 / \mathrm{PMC}$ & $13.3 / 13.5 / 15.0$ & \\
\hline
\end{tabular}




\begin{tabular}{|c|c|c|c|}
\hline Channel & Band / Target & $\begin{array}{c}\text { Background Counts } \\
\text { (Cold / Nominal / Warm) }\end{array}$ & $\begin{array}{c}\Delta V \text { SNR Margin } \\
\text { (Cold / Nominal / Warm) }\end{array}$ \\
\hline \multirow{2}{*}{3} & $5 / \mathrm{H} 2 \mathrm{O} \mathrm{w}$ & $16.6 / 17.0 / 18.7$ & \multirow{2}{*}{$16.3 / 17.4 / 16.9$} \\
\hline & $6 / \mathrm{H} 2 \mathrm{O} \mathrm{s}$ & $16.1 / 16.3 / 17.6$ & \\
\hline \multirow{2}{*}{4} & $7 / \mathrm{CO} 2 \mathrm{~s}$ & $17.6 / 17.6 / 18.8$ & \multirow{2}{*}{$1.0 / 1.4 / 1.3$} \\
\hline & $8 / \mathrm{CO} 2 \mathrm{w}$ & $16.3 / 16.4 / 17.7$ & \\
\hline \multirow{2}{*}{5} & 9 / $\mathrm{PMC}$ & $18.9 / 19.2 / 20.4$ & \multirow{2}{*}{$3.0 / 3.0 / 3.0$} \\
\hline & 10 / PMC & $19.0 / 19.0 / 20.1$ & \\
\hline \multirow{2}{*}{6} & $11 / \mathrm{CH} 4 \mathrm{~s}$ & $19.1 / 19.2 / 20.6$ & \multirow{2}{*}{$1.3 / 1.3 / 1.3$} \\
\hline & $12 / \mathrm{CH} 4 \mathrm{w}$ & $18.5 / 18.6 / 20.1$ & \\
\hline \multirow{2}{*}{7} & $13 / \mathrm{CO} 2 \mathrm{~s}$ & $14.6 / 15.0 / 16.4$ & \multirow{2}{*}{$1.7 / 1.7 / 1.8$} \\
\hline & $14 / \mathrm{CO} 2 \mathrm{w}$ & $15.3 / 15.9 / 17.0$ & \\
\hline \multirow{2}{*}{8} & $15 / \mathrm{NO} \mathrm{w}$ & $11.4 / 12.0 / 12.6$ & \multirow{2}{*}{$0.9 / 0.9 / 1.0$} \\
\hline & $16 / \mathrm{NO} s$ & $14.9 / 15.9 / 15.6$ & \\
\hline
\end{tabular}

\section{CONCLUSION}

SOFIE calibration presented a number of unique and difficult challenges to the team at SDL. In cooperation with scientists at GATS, Inc., new approaches were devised and combined with methods used in previous IR calibrations, resulting in a successful instrument calibration. Experiments were successfully performed to measure SOFIE performance in spectral, spatial, temporal, and radiometric domains, resulting in a complete set of calibration parameters. Acceptable performance relative to program requirements has been demonstrated, and work is ongoing to refine science analysis tools using the measured parameters. SOFIE is ready to go to work.

i. Kemp, J., E. R. Huppi, and M. Madigan, "Measurements of High Out-of-Band Filter Rejection Characteristics," Proc. of SPIE 1112:433-441, 1989.

ii. Theocharous, E., J. Ishii and N. P. Fox, “Absolute linearity measurements on HgCdTe detectors in the infrared region," Applied Optics Vol. 43, No. 21, 4182-4188, July 2004. 